\title{
Discrete choice experiment for eliciting preference for health services for patients with ALS and their informal caregivers
}

\author{
Katy Tobin ${ }^{1 * \dagger} \mathbb{D}$, Sinead Maguire ${ }^{2,3 \dagger}$, Bernie Corr ${ }^{2}$, Charles Normand ${ }^{4}$, Orla Hardiman ${ }^{2,3,5+}$ and Miriam Galvin ${ }^{3 \dagger}$
}

\begin{abstract}
Background: Amyotrophic Lateral Sclerosis (ALS) is a progressive neurodegenerative condition with a mean life expectancy of 3 years from first symptom. Understanding the factors that are important to both patients and their caregivers has the potential to enhance service delivery and engagement, and improve efficiency. The Discrete Choice Experiment (DCE) is a stated preferences method which asks service users to make trade-offs for various attributes of health services. This method is used to quantify preferences and shows the relative importance of the attributes in the experiment, to the service user.
\end{abstract}

Methods: A DCE with nine choice sets was developed to measure the preferences for health services of ALS patients and their caregivers and the relative importance of various aspects of care, such as timing of care, availability of services, and decision making. The DCE was presented to patients with ALS, and their caregivers, recruited from a national multidisciplinary clinic. A random effects probit model was applied to estimate the impact of each attribute on a participant's choice.

Results: Patients demonstrated the strongest preferences about timing of receiving information about ALS. A strong preference was also placed on seeing the hospice care team later rather than early on in the illness. Patients also indicated their willingness to consider the use of communication devices. Grouping by stage of disease, patients who were in earlier stages of disease showed a strong preference for receipt of extensive information about ALS at the time of diagnosis. Caregivers showed a strong preference for engagement with healthcare professionals, an attribute that was not prioritised by patients.

Conclusions: The DCE method can be useful in uncovering priorities of patients and caregivers with ALS. Patients and caregivers have different priorities relating to health services and the provision of care in ALS, and patient preferences differ based on the stage and duration of their illness. Multidisciplinary teams must calibrate the delivery of care in the context of the differing expectations, needs and priorities of the patient/caregiver dyad.

Keywords: Discrete choice experiment, Amyotrophic Lateral sclerosis, Patient preference, Caregiver preference, Health services

\footnotetext{
* Correspondence: katy.tobin@tcd.ie

${ }^{\dagger}$ Katy Tobin, Sinead Maguire, Orla Hardiman and Miriam Galvin contributed equally to this work.

${ }^{1}$ Global Brain Health Institute, School of Medicine, Trinity College Dublin, Dublin, Ireland

Full list of author information is available at the end of the article
} 


\section{Background}

Amyotrophic Lateral Sclerosis (ALS) is a progressive neurodegenerative condition with a mean life expectancy of 3 years from first symptom. There is no effective disease modifying treatment, and management is symptomatic and palliative.

Incorporating the needs of patients and caregivers into the evaluation and development of health services is now recognized as best practice, and most service development and health research protocols require the inclusion of the patient voice. Effective management of ALS depends not only on expertise within the clinical domain, but also on ensuring that impact on the patient, family, health and social environments has been evaluated and addressed. This is because values attributed by patients and caregivers do not always align with those attributed by healthcare professionals [1], and a full understanding of the factors that are important to the service user has the potential to enhance service delivery and engagement and improve efficiency. Additionally, recognizing that some aspects of care provision can be objectively beneficial but unattractive to users is important [2]. Such insights can help to adjust the manner by which care is delivered, taking into account the autonomy of patients and the needs of caregivers, and can also help to inform and improve communication between providers and users of services.

Understanding the perspectives and complex needs of both patients and their caregivers is often challenging for health care professionals. There may be competing benefits and limitations that are difficult to disentangle from the perspective of those providing care within a multidisciplinary clinic [3]. Various methodologies have been utilized by clinic providers to determine the views of patients and caregivers ranging from quantitative (questionnaire) based analyses, mixed methods, and qualitative studies in which patient and caregivers are interviewed and thematic analysis performed. Each methodology has strengths and weaknesses [4-7]. In ALS, qualitative research with patients and caregivers has explored needs [8-12], decision making [13, 14], experience of services $[15,16]$ and communication preferences $[17,18]$. Effective decision-making in ALS occurs when patients' values are supported by care providers [14]. The application of a DCE methodology in this study provides the opportunity to elicit the preferences of patients and caregivers regarding treatment and care options.

Additional mathematical based experimental paradigms can be applied to determine the perspective of service users, including the concept of the discrete choice experiment. The Discrete Choice Experiment (DCE) is a stated preferences method used frequently in economic research, which asks service users to make trade-offs for various attributes of health services. This method is used to quantify preferences and shows the relative importance of the attributes in the experiment, to the service user.

This is increasingly used in the health sector to evaluate interventions and understand the preferences of service users [19-22]. The method has been applied in palliative care to elicit preferences for the types of services available [23]. In that setting, the highest value was placed on the availability of specialist therapies, above medical support.

In a DCE, participants are asked to choose between pairs of choice profiles. The profiles are made up of several attributes which describe aspects of healthcare provision and health services, and each attribute is made up of different levels [22].

Here, we aim to use a DCE to measure the preferences for health services of ALS patients and caregivers and the relative importance of various aspects of care, such as timing of care, availability of services, and decision making. We also aim to determine whether preferences vary by sex, type of ALS onset and stage of disease to gain insights which may inform how care is delivered.

\section{Methods}

This DCE presented participants with a series of choice sets, made up of a number of attributes and levels. Participants were asked to choose between two alternative packages of care in each choice set. This forces the participant to make trade-offs between their preferred and less preferred attribute levels. Analysis of these choices provides a measure of utility for each attribute level. The analysis can also test whether additional factors such as demographics and clinical characteristics are associated with different preferences.

\section{Development of attributes and levels}

The attributes and levels for use in this DCE were derived using a phased approach. In the first phase, the patient journey of 100 patients with ALS were reviewed from first symptom to death. From this, 20 vignettes were developed to represent a spectrum of patient journeys.

In the second phase of development, the patient vignettes were presented to members of the clinical multidisciplinary team (MDT), palliative care clinicians and experts in healthcare management $(n=5)$ for roundtable discussion. This group met four times to determine the attributes that were relevant to patients and caregivers, as defined by the MDT and palliative care team. A set of attributes (13 for patients, 11 for caregivers) were defined for the experiment, with either two or three levels each (Table 1). The attributes and levels were randomised into choice sets using the 
Table 1 Attributes and levels for patient and caregiver experiment

\begin{tabular}{|c|c|c|c|}
\hline Attribute Description & Levels & $\begin{array}{l}\text { Included in } \\
\text { Patient DCE }\end{array}$ & $\begin{array}{l}\text { Included in } \\
\text { Caregiver DCE }\end{array}$ \\
\hline Disease Information & $\begin{array}{l}\text { A1. I would get all the information about motor neuron disease } \\
\text { at the time of diagnosis } \\
\text { A2. I would get all information about motor neuron disease } \\
\text { when I think I will need it } \\
\text { A3. I don't want to know anything about motor neuron disease } \\
\text { at any time }\end{array}$ & $\checkmark$ & $\checkmark$ \\
\hline Price of additional services & $\begin{array}{l}\text { B1. All services would be free } \\
\text { B2. Extra services provided will cost } 80 \text { euro per visit, for example } \\
\text { physiotherapy or speech and language therapy visit } \\
\text { B3. Extra services provided will cost } 40 \text { euro per visit, for example } \\
\text { physiotherapy or speech and language therapy visit }\end{array}$ & $\checkmark$ & $\checkmark$ \\
\hline Arranging visits & $\begin{array}{l}\text { C1. I would get regular visits from community multidisciplinary } \\
\text { team (for e.g. physiotherapy, occupational therapist) and the } \\
\text { public health nurse in my home } \\
\text { C2. I would arrange multidisciplinary team (for e.g. physiotherapy, } \\
\text { occupational therapist) and public health nurse visits as I need in } \\
\text { my home }\end{array}$ & $\checkmark$ & $\checkmark$ \\
\hline Distant to clinic & $\begin{array}{l}\text { D1. I would attend Multidisciplinary team MND specialist clinic } \\
\text { no matter how far away } \\
\text { D2. I would just attend a local Neurology clinic }\end{array}$ & $\checkmark$ & $\checkmark$ \\
\hline Waiting times & $\begin{array}{l}\text { E1. I would be prepared to go to a multidisciplinary clinic with } \\
\text { long waiting times in the clinic to see more than one } \\
\text { professional } \\
\text { E2. I would not be prepared to go to a multidisciplinary clinic } \\
\text { with long waiting times in the clinic to see more than one } \\
\text { professional }\end{array}$ & $\checkmark$ & $\checkmark$ \\
\hline Place of care & $\begin{array}{l}\text { F1. No matter what I would like to receive all my care at home } \\
\text { F2. I would receive care in a hospital or a hospice as an inpatient }\end{array}$ & $\checkmark$ & $\checkmark$ \\
\hline Decisions on care & $\begin{array}{l}\text { G1. The doctors advise and help me when I need treatments } \\
\text { including ventilation and stomach tube } \\
\text { G2. The doctors advise me, and I would decide what treatments } \\
\text { I get including ventilation and stomach tube }\end{array}$ & $\checkmark$ & \\
\hline Personal care provision & $\begin{array}{l}\text { H1. Personal care in the home is provided to me by someone } \\
\text { who is not a relative or friend } \\
\mathrm{H} 2 \text {. Personal care in the home is provided by a relative or friend }\end{array}$ & $\checkmark$ & $\checkmark$ \\
\hline Timing of hospice care & $\begin{array}{l}\text { 11. I would start to see the Hospice Care team early on in my } \\
\text { illness } \\
\text { I2. I would start to see the Hospice Care team when something } \\
\text { serious happens later in my illness }\end{array}$ & $\checkmark$ & \\
\hline Communication devices & $\begin{array}{l}\text { J1. I would use new communication technology including voice } \\
\text { banking } \\
\text { J2. I would not use new communication technology including } \\
\text { voice banking }\end{array}$ & $\checkmark$ & \\
\hline Availability of phone advice & $\begin{array}{l}\text { K1. Phone advice is not available } \\
\text { K2. Phone advice is available } 24 \mathrm{~h} \text { a day } \\
\text { K3. Phone advice is available during the hours of } 9 \mathrm{am}-5 \mathrm{pm} \\
\text { Monday to Friday }\end{array}$ & $\checkmark$ & $\checkmark$ \\
\hline Provision of emotional support & $\begin{array}{l}\text { L1. Emotional support is not provided } \\
\text { L2. Emotional support is provided by group meetings with other } \\
\text { MND patients } \\
\text { L3. Emotional support is provided from a counselor }\end{array}$ & $\checkmark$ & $\checkmark$ \\
\hline $\begin{array}{l}\text { Dependable Healthcare } \\
\text { professionals }\end{array}$ & $\begin{array}{l}\text { M1. I would have healthcare professionals who I can depend on } \\
\text { M2. I would not necessarily need healthcare professionals to } \\
\text { depend on }\end{array}$ & $\checkmark$ & $\checkmark$ \\
\hline Who helps in the home & $\begin{array}{l}\text { N1. I would have non-related individuals in my house to provide } \\
\text { home help for my loved one } \\
\text { N2. I would not have non-related individuals in my house to } \\
\text { provide home help for my loved one }\end{array}$ & & $\checkmark$ \\
\hline
\end{tabular}

The wording in this table was used for the patient DCE. In the caregiver DCE the wording was changed to reflect the caregiver's perspective. For example in Attribute C1 the wording changed from "I would get regular visits" to "My loved one would get regular visits" 
rotation design method [24]. Choice sets were randomised into four blocks, and each participant was shown one block.

The third phase of development comprised a pilot study within which a sample of five patients and five caregivers were asked to participate in the DCE and review and provide feedback on the attributes and levels, and the number of choice sets presented to them. During the pilot, nine choice sets were presented to each participant, which was not found to be overly burdensome. Participants were asked to choose between two options, an opt-out option was not presented and each choice set had some overlapping levels. The final version of the DCE content was developed following this pilot phase. The final design remained unchanged from the pilot study (Table 1).

\section{Data collection and recruitment}

Patients and their caregivers were recruited on consecutive weeks from a national multidisciplinary clinic as they attended scheduled appointments from April 2014 to May 2015. We aimed to recruit as many participants as possible during this study time frame to achieve a sample that would produce reliable results. Previous research has indicated that sample sizes of approximately $n=20$ typically provide reliable estimates, but larger sample sizes are required for estimating covariate effects [25]. Patients aged 18 years or over who fulfilled the El Escorial Diagnostic Criteria for Possible, Probable or Definite ALS [26], and who were cognitively normal using the Edinburgh Cognitive and Behavioural ALS Screen (ECAS) [27], were eligible to participate. Caregivers of patients who were participating in the study who were aged 18 years or over were eligible to participate. Additional variables (e.g. sex, age, date of diagnosis and site of onset of disease) were collected from study participants and/or medical records.

Consenting participants who met the eligibility criteria were presented with a paper copy of the experiment and asked to give their preferred option from each of the scenarios or choice set presented.

Each choice set consisted of two hypothetical packages of care, and participants were asked to choose the package that they preferred. This process was repeated nine times with each participant. On average the DCE took 20 min to complete for both patients and caregivers.

\section{Statistical design and analysis}

Design of the instrument and analysis of the data were carried out using the support. CEs package [28] in $R$ [29]. The attribute levels were randomised into choice sets using the rotation design method [24]. The choice sets contained all of the attributes, but the levels of each attribute varied across choice sets. A random effects probit model was applied to estimate the impact of each attribute on a participant's choice. The model estimates the coefficient for each attribute level, and the magnitude of the coefficient is related to the tendency for participants to choose that attribute level. A large positive coefficient indicates that study participants preferred that level of the attribute, while a negative coefficient indicates a negative preference for an attribute level. The magnitude of attribute coefficients and their associated 95\% confidence interval were used as an indicator of the strength of participant preferences.

Additional variables were added as binary factors to examine whether different subgroups demonstrate different preferences. The variables included were sex (male or female), site of onset (bulbar or spinal onset), time since diagnosis ( $\leq 6$ months or $>6$ months), and Kings Clinical Staging (Stage 1/2 or Stage 3/4) [30]. Analysis of the patient DCE was stratified to further investigate differences between subgroups of the study sample based on sex, site of onset, King's clinical stage and time since diagnosis.

\section{Results}

\section{Patient DCE}

The demographic characteristics of 93 patients and 56 caregivers are described in Table 2. Recruitment numbers for caregivers were lower than for patients either because patients attended the clinic visit alone, or caregivers chose not to participate $(n=19)$. All patients who

Table 2 Profile of study sample

\begin{tabular}{|c|c|c|}
\hline Characteristics & $\begin{array}{l}\text { Patients } \\
(N=93) \\
\mathrm{n}(\%)\end{array}$ & $\begin{array}{l}\text { Caregivers } \\
(N=56) \\
\mathrm{n}(\%)\end{array}$ \\
\hline Sex: Male & $55(59.1)$ & $21(37.5)$ \\
\hline Mean age (range) & $61(25-86)$ & $51(28-78)$ \\
\hline \multicolumn{3}{|l|}{ Caregiver relationship to patient: } \\
\hline Spouse/partner & - & $36(64.3)$ \\
\hline Child of patient & - & $17(30.4)$ \\
\hline Other & - & $3(5.4)$ \\
\hline \multicolumn{3}{|l|}{ Site of onset: } \\
\hline Bulbar & $23(24.7)$ & - \\
\hline Spinal & $69(74.1)$ & - \\
\hline Cognitive & $1(1.1)$ & - \\
\hline $\begin{array}{l}\text { Median time in months since } \\
\text { diagnosis }\left(Q_{1}, Q_{3}\right)\end{array}$ & $12.2(5.5,30.6)$ & \\
\hline Diagnosis $</=6$ months & $23(24.7)$ & \\
\hline Diagnosis > 6 months & $70(75.3)$ & \\
\hline \multicolumn{3}{|l|}{ King's Clinical Staging } \\
\hline Stage 1 or 2 & $26(28.0)$ & \\
\hline Stage 3 or 4 & $62(66.7)$ & \\
\hline
\end{tabular}


were approached agreed to participate and were consented, and all participants were included in the analysis.

The results of the random effects probit analysis of the patient DCE data are outlined in Table 3. Patients showed strong preferences for three attributes (timing of information, use of hospices services and communication devices, (A, I, J)).

Patients demonstrated the strongest preferences about timing of receiving information about ALS (attribute A). Patients strongly preferred receipt of all information about ALS at the time of diagnosis, rather than when they consider the information to be personally relevant (coefficient: $-0.22,95 \%$ CI: $-0.44,-0.01$ ). A strong preference was also placed on seeing the hospice care team (attribute I) later rather than early on in the illness (coefficient: 0.16, 95\% CI: 0.02, 0.30). Patients also indicated their willingness to consider the use of communication devices (attribute J) (coefficient: -0.14, 95\% CI: - 0.29, $-0.00)$.

All other attributes had small coefficients with wide confidence intervals, indicating that patients showed no strong preference for their inclusion in their healthcare package.

The model shows no significant differences in preferences for the binary factors sex, site of onset, time since diagnosis, or stage of disease. To further investigate subgroup differences, stratified analyses were carried out, dividing the sample according to these binary factors.

The stratified models for the DCE with patients are presented in supplementary Tables 1 and 2 (please see Additional file 1).

When grouped by sex, female patients demonstrate a strong preference for using communication devices (coefficient: $-0.25,95 \%$ CI: $-0.47,-0.21$ ). Males did not show a strong preference for any attribute. When grouped by site of onset, those with bulbar onset ALS were less likely to show any strong preferences. The subgroup of patients with spinal onset ALS showed a preference for delaying engagement with palliative/hospice services (coefficient: 0.17, 95\% CI: 0.01, 0.33).

Grouping by stage of disease, patients who were in earlier stages of disease (King's stage 1 or 2) showed a strong preference for receipt of extensive information about ALS at the time of diagnosis, rather than at a later stage (when clinically relevant)(coefficient: $-0.51,95 \% \mathrm{CI}$ : $-0.99,-0.05)$, or not receiving relevant information at any time during their illness (coefficient: $-0.57,95 \% \mathrm{CI}$ : $-1.05,-0.10)$. Those in later disease stages (King's stage 3 or 4) did not show statistically significant preferences for any attribute.

\section{Caregiver DCE}

Table 4 shows the results of the caregiver DCE estimated using a random effects probit model. In contrast to patients, caregivers showed a strong preference for engagement with healthcare professionals (Attribute M)(coefficient: $-0.21,95 \% \mathrm{CI}$ : - 0.37, - 0.04), an attribute that was not prioritised by patients (Table 3). Sex was not a determining factor for caregiver response, nor was the relationship of the patient to caregiver - although these categories may have been limited by power.

Subgroup analysis of the caregiver DCE data explored differences in preferences based on sex and relationship to the patient (Supplementary Table 3 in Additional file 1). Female caregivers showed a strong preference against receiving emotional support in a group with other caregivers, (coefficient: $-0.40,95 \%$ CI: - 0.72, 0.08). Female caregivers also showed a preference for having healthcare professionals that they could depend on (coefficient: $-0.28,95 \% \mathrm{CI}:-0.50,-0.07)$. This contrasted with male caregivers who did not show any strong preferences.

When grouped by relationship to the patient, those who were caregivers for a parent showed a strong preference for personal care in the home being provided by a relative or friend, rather than someone who is not a relative or friend (coefficient: 0.46, 95\% CI: 0.01, 0.93), while spouses did not show any preferences. Caregivers for parents also preferred that emotional support is provided by a counsellor, rather than not at all (coefficient: 0.42, 95\% CI: 0.06, 0.79), and showed a preference for having healthcare professionals that they could depend on (coefficient: -0.38 , 95\% CI: $-0.70,-0.06)$.

\section{Discussion}

This study aimed to explore the preferences and relative importance of attributes relating to health services for patients with ALS and their informal caregivers using a DCE. To our knowledge, this is the first time this quantitative method has been used to assess preferences in an ALS sample.

The findings demonstrate differences in preferences between those recently diagnosed, and those with a more established diagnosis. Those in early disease stages were more interested in receiving information about their illness at the time of diagnosis, whereas those at a later stage of the disease were less interested in learning everything about the condition. Although the experimental design did not permit explanation of stated preferences, the choices of those in the early stages of disease could be explained by a greater degrees of optimism about outcome, whereas those at later stages of illness had already experienced inexorable decline and increasing disability, but had time to adapt to the implications of their illness.

This is supported by previous research exploring the information seeking behaviours of ALS patients. The 
Table 3 Results of Random effects probit model for patient DCE full analysis, and subgroup analysis by time of diagnosis

\begin{tabular}{|c|c|c|c|}
\hline \multirow[t]{2}{*}{ Attribute } & \multirow{2}{*}{$\begin{array}{l}\text { Full Analysis } \\
\text { Coefficient } \\
\text { (95\% Confidence Interval) }\end{array}$} & \multicolumn{2}{|l|}{ Subgroup Analysis } \\
\hline & & $\begin{array}{l}\text { Diagnosis } \leq 6 \text { months } \\
\text { Coefficient ( } 95 \% \\
\text { Confidence Interval) }\end{array}$ & $\begin{array}{l}\text { Diagnosis > } 6 \text { months } \\
\text { Coefficient }(95 \% \\
\text { Confidence Interval) }\end{array}$ \\
\hline Intercept & $-0.21(-0.49,0.07)$ & $-0.44(-1.03,0.13)$ & $-0.08(-0.39,0.23)$ \\
\hline \multicolumn{4}{|l|}{ Reference level } \\
\hline \multicolumn{4}{|l|}{$\begin{array}{l}\text { A1. I would get all the information about motor neuron } \\
\text { disease at the time of diagnosis }\end{array}$} \\
\hline $\begin{array}{l}\text { A2. I would get all information about motor neuron } \\
\text { disease when I think I will need it }\end{array}$ & $-0.22(-0.44,-0.01)$ & $-0.21(-0.67,0.24)$ & $-0.25(-0.50,-0.01)$ \\
\hline $\begin{array}{l}\text { A3. I don't want to know anything about motor } \\
\text { neuron disease at any time }\end{array}$ & $-0.18(-0.40,0.05)$ & $-0.19(-0.65,0.27)$ & $-0.24(-0.50,0.01)$ \\
\hline B. Price of additional services & $-0.00(-0.00,0.00)$ & $0.00(-0.01,0.01)$ & $0.00(-0.01,0.00)$ \\
\hline \multicolumn{4}{|l|}{ Reference level } \\
\hline \multicolumn{4}{|l|}{$\begin{array}{l}\text { C1. I would get regular visits from community } \\
\text { multidisciplinary team (for e.g. physiotherapy, } \\
\text { occupational therapist) and the public health nurse in } \\
\text { my home }\end{array}$} \\
\hline $\begin{array}{l}\text { C2. I would arrange multidisciplinary team (for e.g. } \\
\text { physiotherapy, occupational therapist) and public } \\
\text { health nurse visits as I need in my home }\end{array}$ & $0.07(-0.08,0.22)$ & $0.05(-0.26,0.35)$ & $0.02(-0.16,0.19)$ \\
\hline \multicolumn{4}{|l|}{ Reference level } \\
\hline \multicolumn{4}{|l|}{$\begin{array}{l}\text { D1. I would attend Multidisciplinary team MND specialist } \\
\text { clinic no matter how far away }\end{array}$} \\
\hline D2. I would just attend a local Neurology clinic & $-0.11(-0.31,0.08)$ & $-0.14(-0.55,0.26)$ & $-0.01(-0.23,0.22)$ \\
\hline \multicolumn{4}{|l|}{ Reference level } \\
\hline \multicolumn{4}{|l|}{$\begin{array}{l}\text { E1. I would be prepared to go to a multidisciplinary clinic } \\
\text { with long waiting times in the clinic to see more than } \\
\text { one professional }\end{array}$} \\
\hline $\begin{array}{l}\text { E2. I would not be prepared to go to a } \\
\text { multidisciplinary clinic with long waiting times in } \\
\text { the clinic to see more than one professional }\end{array}$ & $0.04(-0.13,0.22)$ & $0.27(-0.09,0.64)$ & $0.00(-0.20,0.20)$ \\
\hline \multicolumn{4}{|l|}{ Reference level } \\
\hline \multicolumn{4}{|l|}{$\begin{array}{l}\text { F1. No matter what I would like to receive all my care } \\
\text { at home }\end{array}$} \\
\hline $\begin{array}{l}\text { F2. I would receive care in a hospital or a hospice as } \\
\text { an inpatient }\end{array}$ & $-0.05(-0.20,0.11)$ & $-0.08(-0.24,0.04)$ & $-0.06(-0.24,0.12)$ \\
\hline \multicolumn{4}{|l|}{ Reference level } \\
\hline \multicolumn{4}{|l|}{$\begin{array}{l}\text { G1. The doctors advise and help me when I need } \\
\text { treatments including ventilation and stomach tube }\end{array}$} \\
\hline $\begin{array}{l}\text { G2. The doctors advise me, and I would decide } \\
\text { what treatments I get including ventilation and } \\
\text { stomach tube }\end{array}$ & $-0.11(-0.26,0.03)$ & $-0.35(-0.67,-0.05)$ & $-0.07(-0.23,0.10)$ \\
\hline \multicolumn{4}{|l|}{ Reference level } \\
\hline \multicolumn{4}{|l|}{$\begin{array}{l}\text { H1. Personal care in the home is provided to me by } \\
\text { someone who is not a relative or friend }\end{array}$} \\
\hline $\mathrm{H}$ 2. Personal care in the home is provided by a & $-0.04(-0.23,0.16)$ & $-0.28(-0.73,0.17)$ & $0.00(-0.22,0.22)$ \\
\hline
\end{tabular}
relative or friend

Reference level

11. I would start to see the Hospice Care team early on in my illness

12. I would start to see the Hospice Care team when something serious happens later in my illness 
Table 3 Results of Random effects probit model for patient DCE full analysis, and subgroup analysis by time of diagnosis (Continued)

\begin{tabular}{|c|c|c|c|}
\hline \multirow[t]{2}{*}{ Attribute } & \multirow{2}{*}{$\begin{array}{l}\text { Full Analysis } \\
\text { Coefficient } \\
\text { ( } 95 \% \text { Confidence Interval) }\end{array}$} & \multicolumn{2}{|l|}{ Subgroup Analysis } \\
\hline & & $\begin{array}{l}\text { Diagnosis } \leq 6 \text { months } \\
\text { Coefficient ( } 95 \% \\
\text { Confidence Interval) }\end{array}$ & $\begin{array}{l}\text { Diagnosis > } 6 \text { months } \\
\text { Coefficient ( } 95 \% \\
\text { Confidence Interval) }\end{array}$ \\
\hline \multicolumn{4}{|l|}{ Reference level } \\
\hline \multicolumn{4}{|l|}{$\begin{array}{l}\text { J1. I would use new communication technology including } \\
\text { voice banking }\end{array}$} \\
\hline $\begin{array}{l}\text { J2. I would not use new communication technology } \\
\text { including voice banking }\end{array}$ & $-0.14(-0.29,-0.00)$ & $-0.01(-0.33,0.30)$ & $-0.17(-0.33,-0.00)$ \\
\hline \multicolumn{4}{|l|}{ Reference level } \\
\hline \multicolumn{4}{|l|}{ K1. Phone advice is not available } \\
\hline K2. Phone advice is available $24 \mathrm{~h}$ a day & $0.04(-0.16,0.23)$ & $-0.06(-0.47,0.34)$ & $0.00(-0.22,0.22)$ \\
\hline $\begin{array}{l}\text { K3. Phone advice is available during the hours of } \\
9 \mathrm{am}-5 \mathrm{pm} \text { Monday to Friday }\end{array}$ & $-0.09(-0.24,0.05)$ & $-0.05(-0.35,0.24)$ & $-0.11(-0.28,0.05)$ \\
\hline \multicolumn{4}{|l|}{ Reference level } \\
\hline \multicolumn{4}{|l|}{ L1. Emotional support is not provided } \\
\hline $\begin{array}{l}\text { L2. Emotional support is provided by group meetings } \\
\text { with other MND caregivers }\end{array}$ & $0.04(-0.15,0.23)$ & $0.03(-0.15,0.20)$ & $0.01(-0.21,0.24)$ \\
\hline L3. Emotional support is provided from a counselor & $0.02(-0.13,0.17)$ & $0.03(-0.30,0.36)$ & $0.03(-0.15,0.20)$ \\
\hline \multicolumn{4}{|l|}{ Reference level } \\
\hline \multicolumn{4}{|l|}{$\begin{array}{l}\text { M1. I would have healthcare professionals who I can } \\
\text { depend on }\end{array}$} \\
\hline $\begin{array}{l}\text { M2. I would not necessarily need healthcare } \\
\text { professionals to depend on }\end{array}$ & $0.10(-0.08,0.28)$ & $0.42(0.02,0.83)$ & $0.09(-0.12,0.30)$ \\
\hline Site of Onset & $-0.07(-0.28,0.13)$ & $-0.2(-0.64,0.24)$ & $-0.09(-0.34,0.16)$ \\
\hline Time Since Diagnosis & $-0.01(-0.24,0.21)$ & - & - \\
\hline Sex & $-0.04(-0.24,0.14)$ & $0.39(-0.25,0.73)$ & $-0.12(-0.35,0.09)$ \\
\hline Kings Staging & $0.13(-0.08,0.34)$ & $0.24(-0.25,0.73)$ & $0.00(-0.24,0.25)$ \\
\hline Rho-squared & 0.13 & 0.2 & 0.1 \\
\hline Adjusted rho-squared & 0.09 & 0.08 & 0.07 \\
\hline
\end{tabular}

The magnitude of the coefficient is related to the tendency for participants to choose that attribute level. The magnitude of attribute coefficients and their associated $95 \%$ confidence interval were used as an indicator of the strength of participant preferences

majority of patients and caregivers search for additional information after diagnosis $[17,18]$.

Our data also suggest that sensitive imparting of knowledge is appropriate at the time of diagnosis, although this must also be driven by the preferences of the patient, which is in turn informed by the stage of disease.

Despite best practice guidelines/evidence relating to the benefits of the early introduction of palliative care services from diagnosis, our data suggest that patients do not wish to engage with hospice/palliative care until later stages of the illness. This finding is consistent with previous qualitative ALS research which showed that control over accessing health services is of major importance, and participants expect to engage with services when they feel ready [31]. The findings also support the work of Foley et al., [31] which showed that patients consider hospice or palliative care as end-of-life care, even though all ALS care takes a palliative approach [32].

Patients ranked as important the provision and use of communication devices, although subgroup analysis shows this was not associated with bulbar onset of disease. As the type of communication device was not specified, this ranking may have reflected a general concern about loss of ability to communicate, rather than a specific engagement with technology. This is supported by an association between this preference and duration of illness, but not with site of onset of disease (bulbar versus spinal onset).

Our data have demonstrated a significant and important divergence between patient and caregivers with respect to priortised attributes. Caregivers consistently placed the highest value on external professional support. These attributes were not prioritised by patients. Similarly attributes that were valued by patients (timing 
Table 4 Results of Random effects probit model for caregiver DCE

\begin{tabular}{|c|c|c|}
\hline Attribute & Coefficient & 95\% Confidence Interval \\
\hline Intercept & -0.09 & $-0.29,0.10$ \\
\hline \multicolumn{3}{|l|}{ Reference level } \\
\hline \multicolumn{3}{|l|}{ A1. I would get all the information about motor neuron disease at the time of diagnosis } \\
\hline A2. I would get all information about motor neuron disease when I think I will need it & 0.03 & $-0.23,0.29$ \\
\hline A3. I don't want to know anything about motor neuron disease at any time & -0.01 & $-0.27,0.25$ \\
\hline B. Price of additional services & -0.00 & $-0.00,0.00$ \\
\hline \multicolumn{3}{|l|}{ Reference level } \\
\hline \multicolumn{3}{|l|}{$\begin{array}{l}\text { C1. My loved one would get regular visits from community multidisciplinary team } \\
\text { (for e.g. physiotherapy, occupational therapist) and the public health nurse at home }\end{array}$} \\
\hline $\begin{array}{l}\text { C2. My loved one would arrange multidisciplinary team (for e.g. physiotherapy, } \\
\text { occupational therapist) and public health nurse visits as they need at home }\end{array}$ & -0.11 & $-0.29,0.07$ \\
\hline \multicolumn{3}{|l|}{ Reference level } \\
\hline \multicolumn{3}{|l|}{ D1. I would attend Multidisciplinary team MND specialist clinic no matter how far away } \\
\hline D2. I would just attend a local Neurology clinic & -0.09 & $-0.33,0.15$ \\
\hline \multicolumn{3}{|l|}{ Reference level } \\
\hline \multicolumn{3}{|l|}{$\begin{array}{l}\text { E1. I would be prepared to go to a multidisciplinary clinic with long waiting times in the } \\
\text { clinic to see more than one professional }\end{array}$} \\
\hline $\begin{array}{l}\text { E2. I would not be prepared to go to a multidisciplinary clinic with long waiting times } \\
\text { in the clinic to see more than one professional }\end{array}$ & 0.09 & $-0.12,0.30$ \\
\hline \multicolumn{3}{|l|}{ Reference level } \\
\hline \multicolumn{3}{|l|}{ F1. No matter what I would like my loved one to receive all care at home } \\
\hline F2. My loved one would receive care in a hospital or a hospice as an inpatient & -0.08 & $-0.27,0.11$ \\
\hline \multicolumn{3}{|l|}{ Reference level } \\
\hline \multicolumn{3}{|l|}{ H1. Personal care in the home is provided by someone who is not a relative or friend } \\
\hline H2. Personal care in the home is provided by a relative or friend & 0.14 & $-0.09,0.36$ \\
\hline \multicolumn{3}{|l|}{ Reference level } \\
\hline \multicolumn{3}{|l|}{ K1. Phone advice is not available } \\
\hline K2. Phone advice is available $24 \mathrm{~h}$ a day & 0.22 & $-0.01,0.45$ \\
\hline K3. Phone advice is available during the hours of $9 \mathrm{am}-5 \mathrm{pm}$ Monday to Friday & 0.11 & $-0.06,0.29$ \\
\hline \multicolumn{3}{|l|}{ Reference level } \\
\hline \multicolumn{3}{|l|}{ L1. Emotional support is not provided } \\
\hline L2. Emotional support is provided by group meetings with other MND caregivers & -0.20 & $-0.43,0.04$ \\
\hline L3. Emotional support is provided from a counselor & -0.02 & $-0.21,0.16$ \\
\hline \multicolumn{3}{|l|}{ Reference level } \\
\hline \multicolumn{3}{|l|}{ M1. I would have healthcare professionals who I can depend on } \\
\hline M2. I would not necessarily need healthcare professionals to depend on & -0.21 & $-0.37,-0.04$ \\
\hline \multicolumn{3}{|l|}{ Reference level } \\
\hline \multicolumn{3}{|l|}{ N1. I would have non-related individuals in my house to provide home help for my loved one } \\
\hline $\begin{array}{l}\text { N2. I would not have non-related individuals in my house to provide home help for } \\
\text { my loved one }\end{array}$ & -0.06 & $-0.23,0.11$ \\
\hline Sex & -0.14 & $-0.38,0.09$ \\
\hline Relationship to patient & -0.02 & $-0.23,0.18$ \\
\hline Rho-squared $=0.05$ & & \\
\hline
\end{tabular}

Rho-squared $=0.05$

The magnitude of the coefficient is related to the tendency for participants to choose that attribute level. The magnitude of attribute coefficients and their associated $95 \%$ confidence interval were used as an indicator of the strength of participant preferences 
of information about the illness, and availability of communication aids) were not prioritized by caregivers.

In general, patients tended to demonstrate preferences toward clinical aspects of their illness (obtaining information about disease progression and prognosis) while caregivers focussed on services and supports that could assist them.

Perhaps surprisingly, neither patients or caregivers prioritized access to specialist multidisciplinary clinics, although there is a strong evidence base indicating that specialist multidisciplinary care improves quality of life and clinical outcome. Additional work is required to ascertain the reasons for this, and to determine how best to ensure that patients and caregivers are provided with sufficient information to enable them make informed decisions about their preference for attending a non-specialist rather than a specialist clinic. Both patients and caregivers eschewed early engagement with palliative care/hospice services. This is consistent with other work suggesting that engagement with palliative care is perceived to be an admission by healthcare professional as an end stage intervention. Education and communication regarding the benefits of specialist multidisciplinary and the early introduction of palliative care (at the time of diagnosis) is required to ensure that patients and their caregivers can make informed choices about evidence based options for care.

This study has limitations. It was crossectional in design and does not provide any information regarding evolution of preferences by patients and caregivers. Only patients who attend the national MND clinic and were well enough to attend were available for study selection. The findings are limited to the set of attributes and levels that were selected for inclusion in the DCE. It is also important to note that subanalyses are limited by sample size and the model may have missed some strong preferences for specific subgroups, as in the subgroup with bulbar onset and caregiver relationship subgroup. Other factors such as marital status, education, income and age may have a significant influence on preferences.

\section{Conclusions}

This study demonstrates that the DCE method can be useful in uncovering priorities of patients and caregivers with ALS that might not be identified using other research methods. Our data show that patients and caregivers have different priorities relating to health services and the provision of care in ALS, and that patient preferences differ based on the stage and duration of their illness.

The study suggests that the multidisciplinary team must calibrate the delivery of care in the context of the differing expectations, needs and priorities of the patient/caregiver dyad, and that communication as to the likely benefits of evidence based multidisciplinary and palliative care require prioritisation.

\section{Supplementary Information}

The online version contains supplementary material available at https://doi. org/10.1186/s12913-021-06191-z.

Additional file1: Supplementary Tables. This file includes additional analyses of subgroup data. Table $\mathbf{1}$. Results of Random effects probit model for patient DCE - Gender and Site of Onset subgroup analysis. Table 2. Results of Random effects probit model for patient DCE - Time since diagnosis and King's Staging subgroup analysis. Table 3. Results of Random effects probit model for caregiver DCE - Sex and Relationship to patient subgroup analysis.

\section{Abbreviations}

ALS: Amyotrophic Lateral Sclerosis; DCE: Discrete Choice Experiment; MDT: Multidisciplinary Team

\section{Acknowledgements}

We would like to thank study participants for their involvement in the study, and the charities Research Motor Neurone and the Irish Motor Neurone

Disease Association for their support.

\section{Authors' contributions}

$K T$ contributed to the design of the study, analysed and interpreted the data and contributed to the manuscript. SM contributed to the design of the study, carried out all data collection, interpreted findings and contributed to the manuscript. BC contributed to the design of the study and contributed to the manuscript. CN contributed to the design of the study and contributed to the manuscript. OH contributed to the design of the study, interpreted findings and contributed to the manuscript. MG contributed to the design of the study, interpreted findings and contributed to the manuscript. All authors read and approved the final manuscript

\section{Funding}

Funding for this study was from the Health Research Board, ICE/2012/6. The HRB had no role in the execution of the study.

\section{Availability of data and materials}

The datasets used and/or analysed during the current study are available from the corresponding author on reasonable request.

Ethics approval and consent to participate

Fully-informed written consent was obtained from all participants and this study was approved by Beaumont Hospital Ethics (Medical Research) Committee.

Consent for publication

Not applicable.

Competing interests

$\mathrm{KT} \mathrm{SM}, \mathrm{MG}, \mathrm{OH}, \mathrm{CN}, \mathrm{BC}$ declare that they have no competing interests.

\section{Author details}

${ }^{1}$ Global Brain Health Institute, School of Medicine, Trinity College Dublin, Dublin, Ireland. 'Department of Neurology, National Neuroscience Centre, Beaumont Hospital, Dublin, Ireland. ${ }^{3}$ Academic Unit of Neurology, Trinity Biomedical Sciences Institute, Trinity College Dublin, Dublin, Ireland. ${ }^{4}$ Centre for Health Policy and Management, School of Medicine, Trinity College Dublin, Dublin, Ireland. ${ }^{5}$ FutureNeuro SFI Research Centre, Royal College of Surgeons in Ireland, Dublin, Ireland.

Received: 5 May 2020 Accepted: 18 February 2021

Published online: 09 March 2021

\section{References}

1. Elf M, Flink M, Nilsson M, Tistad M, Von Koch L, Ytterberg C. The case of value-based healthcare for people living with complex long-term conditions. BMC Health Serv Res. 2017;17(1):1-6. Available from: http:// bmchealthservres.biomedcentral.com/articles/10.1186/s12913-016-1957-6 [cited 2020 Nov 29] 
2. Tistad M, Ytterberg C, Tham K, Von Koch L. Poor concurrence between disabilities as described by patients and established assessment tools three months after stroke: A mixed methods approach. J Neurol Sci. 2012;313(12):160-166. Available from: http://www.jns-journal.com/article/S0022510X11 005351/fulltext [cited 2020 Nov 30]

3. Foley $G$, Hynes $G$. Decision-making among patients and their family in ALS care: a review. Amyotroph Lateral Scler Frontotemporal Degener. 2018;19(34):173-93. https://doi.org/10.1080/21678421.2017.1353099.

4. Stephens HE, Felgoise S, Young J, Simmons Z. Multidisciplinary ALS clinics in the USA: A comparison of those who attend and those who do not. Amyotroph Lateral Scler Front Degener. 2015;16(3-4):196-201. Available from: http://www.ncbi.nlm.nih.gov/pubmed/25602166 [cited 2020 Apr 20].

5. Stephens HE, Young J, Felgoise SH, Simmons Z. A qualitative study of multidisciplinary ALS clinic use in the United States. Amyotroph Lateral Scler Front Degener. 2016;17(1-2):55-61. Available from: http://www.ncbinlm.nih. gov/pubmed/26508132 [cited 2020 Apr 20].

6. Van Den Berg JP, Kalmijn S, Lindeman E, Veldink JH, De Visser M, Van Der Graaff MM, et al. Multidisciplinary ALS care improves quality of life in patients with ALS. Neurology. 2005;65(8):1264-1267. Available from: http:// www.ncbi.nlm.nih.gov/pubmed/16247055 [cited 2020 Apr 20].

7. Hobson E V., Baird WO, Partridge R, Cooper CL, Mawson S, Quinn A, et al. The TiM system: developing a novel telehealth service to improve access to specialist care in motor neurone disease using user-centered design. Amyotroph Lateral Scler Front Degener 2018;19(5-6):351-361. Available from: http://www.ncbi.nlm.nih.gov/pubmed/29451026 [cited 2020 Apr 20].

8. Ang K, Umapathi T, Tong J, Ng J, Tseng L, Woo IMH. Healthcare needs of patients with amyotrophic Lateral sclerosis (ALS) in Singapore: a patientcentred qualitative study from multiple perspectives. J Palliat Care. 2015; 31(3):150-7.

9. Weisser FB, Bristowe K, Jackson D. Experiences of burden, needs, rewards and resilience in family caregivers of people living with motor Neurone disease/amyotrophic Lateral sclerosis: a secondary thematic analysis of qualitative interviews. Palliat Med. 2015;29(8):737-45.

10. Bolmsjo I, Hermeren G. Interviews with patients, family, and caregivers in amyotrophic lateral sclerosis: comparing needs. J Palliat Care. 2001;17(4): 236-40.

11. Ferullo CM, Mascolo M, Ferrandes G, Caponnetto C. Amyotrophic lateral sclerosis: an assessment of the needs of patients and caregivers in the Liguria region of Italy. G Ital Med Lav Ergon. 2009;31(1 Suppl A):A16-23.

12. Williams MT, Donnelly JP, Holmlund T, Battaglia M. ALS: family caregiver needs and quality of life. Amyotroph Lateral Scler. 2008;9(5):279-86.

13. Hogden A, Greenfield D, Nugus P, Kiernan MC. Development of a model to guide decision making in amyotrophic lateral sclerosis multidisciplinary care. Heal Expect An Int J Public Particip Heal Care Heal policy. 2015;18(5):1769-82.

14. Hogden A, Greenfield D, Nugus P, Kiernan MC. What influences patient decision-making in amyotrophic lateral sclerosis multidisciplinary care? A study of patient perspectives. Patient Prefer Adherence. 2012;6:829-38

15. Foley $G$, Timonen V, Hardiman O. Experience of services as a key outcome in amyotrophic lateral sclerosis (ALS) care: the case for a better understanding of patient experiences. Am J Hosp Palliat Care. 2012;29(5): 362-367. Available from: http://www.ncbi.nlm.nih.gov/pubmed/21998444 [cited 1 Mar 2013].

16. Foley G, Timonen V, Hardiman O. Patients' perceptions of services and preferences for care in amyotrophic lateral sclerosis: a review. Amyotroph Lateral Scler. 2012:13(1):11-24.

17. Chiò A, Montuschi A, Cammarosano S, De Mercanti S, Cavallo E, llardi A, et al. ALS patients and caregivers communication preferences and information seeking behaviour. Eur J Neurol. 2008;15(1):55-60.

18. Abdulla S, Vielhaber S, Machts J, Heinze $H-J$, Dengler R, Petri S. Information needs and information-seeking preferences of ALS patients and their carers. Amyotroph Lateral Scler Frontotemporal Degener. 2014;15(7-8):505-12.

19. Bridges JFP, Kinter ET, Kidane L, Heinzen RR, McCormick C. Things are Looking up Since We Started Listening to Patients: Trends in the Application of Conjoint Analysis in Health 1982-2007. Patient. 2008;1(4):273282. Available from: http://www.ncbi.nlm.nih.gov/pubmed/22272995 [cited $2018 \mathrm{Jul}$ 4].

20. Ryan M, Gerard K. Using discrete choice experiments to value health care programmes: current practice and future research reflections. Appl Health Econ Health Policy. 2003;2(1):55-64. Available from: http://www.ncbi.nlm.nih. gov/pubmed/14619274 [cited 2018 Jul 4].
21. Marshall D, McGregor SE, Currie G. Measuring Preferences for Colorectal Cancer Screening. Patient Patient-Centered Outcomes Res. 2010;3(2):79-89. Available from: http://www.ncbi.nIm.nih.gov/pubmed/22273359 [cited 2018 Jul 4].

22. Bridges JFP, Hauber AB, Marshall D, Lloyd A, Prosser LA, Regier DA, et al. Conjoint analysis applications in health - a checklist: a report of the ISPOR good research practices for conjoint analysis task force. Value Health 2011: 14(4):403-413.Available from: http://www.ncbi.nlm.nih.gov/pubmed/216693 64 [cited 2014 Jul 10].

23. Douglas H-R, Normand CE, Higginson IJ, Goodwin DM. A new approach to eliciting patients' preferences for palliative day care: the choice experiment method. J Pain Symptom Manag. 2005;29(5):435-445. Available from: http:// www.ncbi.nlm.nih.gov/pubmed/15904746 [cited 2014 Aug 26].

24. Reed Johnson F, Lancsar E, Marshall D, Kilambi V, Mühlbacher A, Regier D A, et al. Constructing experimental designs for discrete-choice experiments: report of the ISPOR Conjoint Analysis Experimental Design Good Research Practices Task Force. Value Health. 2013;16(1):3-13. Available from: http:// www.ncbi.nlm.nih.gov/pubmed/23337210 [cited 2014 Aug 26].

25. Lancsar E, Louviere J. Conducting discrete choice experiments to inform healthcare decision making: A user's guide. Pharmacoeconomics; 2008. 26 p. 661-677. Available from: https://pubmed.ncbi.nlm.nih.gov/18620460/ [cited 2020 Dec 2].

26. Brooks BR, Miller RG, Swash M, Munsat TL. El Escorial revisited: Revised criteria for the diagnosis of amyotrophic lateral sclerosis. Amyotroph Lateral Scler Other Mot Neuron Disord. 2000;1 (5):293-299. Available from: http://www.ta ndfonline.com/doi/full/10.1080/146608200300079536 [cited 2018 Jul 4]

27. Abrahams S, Newton J, Niven E, Foley J, Bak TH. Screening for cognition and behaviour changes in ALS. Amyotroph Lateral Scler Front Degener. 2014;15(1-2):9-14. Available from: http://www.ncbi.nlm.nih.gov/pubmed/23 781974 [cited 2018 Jul 4].

28. Aizaki H. Basic Functions for Supporting an Implementation of Choice Experiments in \{R\}. J Stat Software, Code Snippets. 2012;50(2):1-24 Available from: http://www.jstatsoft.org/v50/c02/.

29. R Core Team. R: A Language and Environment for Statistical Computing. Vienna; 2014. Available from: http://www.r-project.org/

30. Roche JC, Rojas-Garcia R, Scott KM, Scotton W, Ellis CE, Burman R, Wijesekera L, Turner MR, Leigh PN, Shaw CE, Al-Chalabi A. A proposed staging system for amyotrophic lateral sclerosis. Brain. 2012;135(Pt 3):84752. https://doi.org/10.1093/brain/awr351.

31. Foley G, Timonen VHO. Understanding psychosocial processes underpinning engagement with services in motor neurone disease: a qualitative study. Palliat Med. 2014;28:318-25.

32. Andersen PM, Abrahams S, Borasio GD, de Carvalho M, Chio A, Van Damme $P$, et al. EFNS guidelines on the clinical management of amyotrophic lateral sclerosis (MALS)--revised report of an EFNS task force. Eur J Neurol. 2012; 19(3):360-375. Available from: http://www.ncbi.nlm.nih.gov/pubmed/21914 052 [cited 2013 Aug 9].

\section{Publisher's Note}

Springer Nature remains neutral with regard to jurisdictional claims in published maps and institutional affiliations.

Ready to submit your research? Choose BMC and benefit from:

- fast, convenient online submission

- thorough peer review by experienced researchers in your field

- rapid publication on acceptance

- support for research data, including large and complex data types

- gold Open Access which fosters wider collaboration and increased citations

- maximum visibility for your research: over $100 \mathrm{M}$ website views per year

At BMC, research is always in progress.

Learn more biomedcentral.com/submissions 